\title{
Digital Cinematography: The Medium is the Message?
}

\author{
By Sarah Sparke*
}

In 2011 journalist Jaime Weinman wrote that 'as digital becomes the default choice, one thing is clear: It's time to go back to calling the movies "pictures" instead of "films". This paper is a response to the rapid and substantial global changes occurring in moving image technologies, practices and discourses. Here I focus on the importance of choice of categorisation terms such as 'film', 'movie' and 'digital' in shaping not only how we understand what is being categorised, but also how we value it and understand its potential. Building on the Bourdeusian concept of cultural capital in which categorisation - and interpretations of categorisation - of objects/ artefacts and associated behaviours has social sources and uses, I concentrate on the realm of the moving image, and within this, on digital cinema.

\section{Introduction}

In the last few years as a response to technological changes there has been an increase in mainstream press headlines such as:

Digital cinema 'will eclipse' $35 \mathrm{~mm}$ film by early 2012 - and celluloid will disappear by 2015

All UK cinemas will be digital by 2013

End of a format that has been used for 120 years

Directors may still use celluloid to shoot - it's just projectors that will change.

(Rob Waugh, 2011, Daily Mail online)

There can be few of us who are unaware of the recent changes in movie technologies and practices, perhaps from exposure to academic texts such as Enticknap's (2005) Moving Image Technology- From Zoetrope to Digital and from our day-to-day life, for example from media conversations surrounding ground-breaking digitally-led movies such as Avatar (Dec '09) and Gravity (Oct'13).

Whilst these two movies used digital technology explicitly, in most other cases the use of digital technologies has been less visible and less important to the layman ("the story's the thing"). However, for those closely connected with

${ }^{*}$ Researcher, University of the West of England, UK. 
the moving image industry these changes matter, and how one understands the changes and how one talks about them matters. When there is a change in dominance of one 'way it is done' over another, and associated changes in the value of related expertise and knowledge, there are winners and losers and degrees of adaptation. Much of the positioning is carried out through discourse - the 'what is done', 'what is said' - and its interpretation. Those who held high positions within the previous hierarchy may wish to maintain that structure through maintenance of the previous value structures, while others will seek to make change.

There are ongoing and longstanding 'Film Studies' debates on the topic of cinematographic industry change and ontology, which stretch back at least to Bazin. However, much of the emphasis has been on the impact of digitization on viewing practices, content and new ways of understanding the way cinema relates to the world around us, rather than a consideration of the use of language in the power struggles amongst the hierarchy of skills and personnel.

When an influential academic such as Harbord uses the terms 'digital film' (2006) and 'film studies' (2007) in her book titles when she is discussing digital moving image, and Rodowick chooses The virtual life of film (2007), one wonders why the word 'film' has been chosen. When a central theme of the literature is an argument against medium specificity but uses 'film' as the meta-term, a section of the industry wonders if they, and their struggle for recognition of changing technologies of production (and their skill with those new technologies) are still being subsumed.

In contrast, Sean Cubitt, another key author, has preferred to explicitly name alternatives to film (eg Timeshift: on video culture (1991), and Digital Aesthetics (1998)) and to examine the politics of digital production, most recently focusing on the environmental impact of the digitization of movingimage, as in 'Ecomedia Futures' (2014) and 'Angelic Ecologies' (2013). His call for the recognition of the impact of the new technology requires that others clearly acknowledge the changes in medium. That is, the use of 'film' as a blanket term will not do. So although he does not focus on the importance of choice of term in the way that this paper does, it is clearly relevant to his work.

In this paper I suggest that in this period of transition, what one calls the medium matters because it reveals and signals one's position in the debate and hierarchy, one's value systems, and one's cultural capital. It may also signal a willingness to consider the wider implications of the change in technology: as Manovich points out, 'software re-adjusts and re-shapes everything it is applied to - or at least it has the potential to do this.' $(2013, \mathrm{p} 80)$. That is, because conceptions of what a medium 'means' informs how it is used, and by whom, the naming of the medium matters.

\section{"Digital: - Post-Production, Fast Turnover, Better Than Human Eye Film: - Nostalgic, Expensive, Limited." (Final-year undergraduate)}




\section{Cultural Capital and Categorizations}

From the school playground onwards we recognise the way that certain behaviours and vocabularies - as much as physical items such as clothing - can be used to create distinctions between people. However arbitrary and possibly ridiculous these distinctions may be, they are used by all of us to categorise and divide people into 'people like us' and those who aren't. Whilst some of the liminal rules are very obvious, such as school uniform, there are other less obvious rules and interpretations, such as the length of one's tie, or the shape of the knot, which may be 'read' by those 'in the know' (or to be more academic, by those who share that interpretive repertoire) as a signal of belonging to one particular group or another.

Pierre Bourdieu (1984) showed that each section of society has its own systems of distinction based on cultural capital. Everyone has cultural capital, but what that cultural capital is will vary from person to person and from section of society to section of society, and will vary over time. Cultural capital is made up of shared understandings of 'the way it is done'. It involves shared value systems, and shared vocabularies and interpretive repertoires. These discourses and their meanings are fluid rather than fixed, but at any one time members of different groups will recognise those who hold a similar cultural capital, and those who don't.

Cultural capital is learnt from one's parents (and milieu), and they learnt from their parents and so on. This is, cultural capital is acquired through repeated exposure to a particular set of discourses. It is a deep, rich knowledge which informs how one interprets everything, how one categorises it, and also informs how one understands those categories.

As Bourdieu pointed out the other important thing about cultural capital is that just as it is shaped by who one knows and the family/milieu one grew up in, it also signals that social information to other people. That is, one's choice of furniture, art, and hobbies are part of one's general discourse, and people 'read' this type of information, and as in the playground, within different social strata there are those who are considered to be 'in' and those who are not. So whilst society as a whole has a socio-economic hierarchy, there are many hierarchies within the subdivisions, and each uses cultural capital to construct and display distinction and group membership.

Whereas Bourdieu examined a wide range of cultural forms and how they are used by different sections of society, here I concentrate on one small element of mass media: digital moving image technologies.

I examine this on the basis that choice of term one uses for those technologies and outputs and one's interpretation of the term are used to signal social group and status. Do you choose moving pictures, movie, pics, flicks, talkie, motion picture, cinema, film, feature film, feature, moving image, video, dvd.....? That is, whereas Marshal McLuhan (1964) suggested that 'the medium is the message', here I examine the idea that what one calls the medium is also the message. 
I begin with a quick discussion of the area being considered, and its history:

\section{History}

That which is called a film, or movie, or whatever term one chooses, is a combination of the means of data capture, the post-capture editorial work and the means of display.

From the 1890s to the present, recordings of the moving image have been made on celluloid or 'film', and screenings involved a projection of images from that celluloid, or from celluloid copies of the original. The colloquial term 'the flicks', used in the UK from c1926 is thought to refer to the effect given by film in its early days as the projected image moved from one frame to the next ${ }^{1}$.

The 1930's saw the advent of television, which used cathode ray tubes to both transmit and receive images. Although television showed moving image, people did not call watching the television 'watching movies', in large part because the meaning of the term had changed from a truncation of 'moving pictures' to instead mean a particular type of moving image: that which was screened in a cinema and had a particular type of content \& duration.

Since 24 October 2012 all television broadcasts in the United Kingdom have been in a digital format, but not all the content will have been recorded digitally. In cinemas celluloid film has long been used for recording the moving image, then replicated for distribution to multiple cinemas, and then shown by projecting from the celluloid. However, from a slow start in 2005/6 (accelerated by expected demand from audiences for digital 3D films such as Avatar, as well as the significant push from distributors), cinemas have been rapidly converting to digital display, requiring the scanning (conversion) of all non-digital movies.

Whilst at the time of Waugh's item (2011) the Daily Mail appeared to expect directors to still shoot in celluloid, the perceived higher costs of shooting in film ${ }^{2}$, and 'the dramatically advancing digitalization in the motion picture industry' (Fuji, 2012) ${ }^{3}$ was being felt by manufacturers of motion picture film cameras (the last one rolled off the assembly line in 2011), and by the manufacturers of film: Fuji ceased producing motion picture camera filmstock in 2013 (Fuji, 2013), and Agfa had ceased years before that. In contrast Kodak (having filed for bankruptcy in January 2012) announced in

\footnotetext{
${ }^{1}$ The flickering is due to different light levels in the shots (an effect of hand-cranking cameras, which gives slightly uneven exposure times), and of a shutter delay in the projection.

${ }^{2}$ The major drawback of film is the expense. And the expenses of shooting film are well known: stock, processing, and scanning all add up. But what if you were to take the most expensive of these, the scanning, and radically shake up the cost structure?' (John Burkhart, June 2013)

${ }^{3}$ The rate of change was driven by economic imperatives - digital replication and distribution is much cheaper, and this push from distributors through change of product availability forced or encouraged cinemas to convert to digital projectors.
} 
June 2013 that it was still very much in the $35 \mathrm{~mm}$ motion picture film business, although the decision is seen by many as questionable. Although some commentators have argued that the announcement of the death of film is premature, that is a minority view.

'People love film, it's what movies look like, but it's definitely in danger. Film as editing media is utterly dead. Film as deliverable, is dying fast. Film as acquisition format, is still in intensive care.

Current digital cameras are now at about parity with film in terms of resolution and dynamic range. The next generation of digital cameras will probably exceed film in most technical areas. But aesthetics do trump technical specs, especially so in a wholly visual medium. So while digital will dominate (there's no doubt about that), is there still room for film?' (John Burkhart, 2013)

\section{The Advent of Digital Movie-Cameras}

"Fortunately or unfortunately I am old enough to come from when there was only film for cinema. There was no digital apart from DigiBeta, which was reserved to TV work, and didn't intersect with high end cinema work."

(Personal email, professional focus-puller/ DoP)

With the rise of DVDs (digital versatile discs) in the late 1990s replacing VHS (video home system) or Betamax tape, which both held analogue data, and then the rise of cameras which stored all the data on a chip rather than tape, the field moved further away from celluloid. The mass-market breakthrough of domestic DVD recorders and digital video recorders in the late 2000s meant that the means of production was within the grasp of many rather than being the preserve of professionals. However, despite the lack of anything resembling film/tape, people still speak of 'filming' and 'film'. Perhaps for the layman these terms have been around for so long that it is easier to use them even when inaccurate. But for some - notably professionals making the images - the more precise meaning of the choice of term really mattered and matters still.

\section{Choices}

The decision regarding which term to use will depend on one's cultural capital: the distinctions one is aware of and cares about, and (importantly) whether one wishes to share the information that one is aware of and cares about making the those distinctions in that particular context. So choice of term depends not just on the 'what' is known (ie that there are differences) but also the context of a particular conversation or discourse, and whether display 
of that knowledge is considered useful and desirable - ie the 'how to' element within discourse choice.

Given their very close knowledge of the similarities and differences, and their need to protect their position and the status of their knowledge, it is not surprising that at the beginning of the challenge by digital technology film professionals would wish to emphasise the distinction between the two, and to ensure that film and film expertise was held in higher esteem. It is perhaps also not surprising that for some of the early-adopters of digital (particularly the software developers) the aim was to make images that were as much like film aesthetics as possible, whereas for others the aim was to explore the potential capacities and implications of the new medium, clearly positioning digital moving image as 'not film', and positioning themselves as pioneers. To some practitioners, the tendency of others to subsume digital into 'film' is a denial of the new technologies, possibilities, and expertise. As one practitioner acerbically asked an academic recently:

"Why are you calling this 'film'? That is not what I make."

(Field notes, conversation April 2014)

The choice of use of terms is not restricted to people in conversation. Organisations are making the same kinds of choices. For example, the Museum of Modern Art in New York divides its vast archive of moving image work into 2 categories: Media and Performance Art, and Film. According to MOMA,

'The difference between work that is classified as Media and Film has to do with the presentation. Media work is intended to be presented in a gallery, while Film work is intended for one of our theaters.'

(Personal email, 10th April 2014).

That is, the names do not refer to the media used, but reflect the content film is for the cinema, probably involving a storyline, 'media' is for galleries, emphasising 'Art'.

Institutes such as the British Film Institute and its flagship event the BFI London Film Festival are unlikely to change their name in the near future, even with the phasing out of celluloid. The American Film Institute is similarly wedded to its name, whilst acknowledging the importance of digital technology (one of the two sponsors for the AFI 2013 awards lunch was Verizon Digital Media Services).

\section{Who makes a Point of Distinguishing between Media, and why?}

Despite the presence of high-profile precedent offering other terms, such as Walt Disney Pictures (my emphasis), named in 1983, Jaime Weinman's 
suggestion that we "go back to calling the movies "pictures' instead of "films", hasn't caught on. So why not? And does it matter?

Prior work by Bourdieu (1984) and Barthes (1972) and much of the Consumer Culture Theory canon suggests that choice of words and discourses matters because they are understood as social signals and serve social positioning purposes. They also, importantly, inform practices - in this case production practices. Therefore choice of term and how one interprets it will inform whether one engages with a medium, and in what way.

Different sectors, such as the lay public and those involved in the trade, have and use different interpretive repertoires, and their choice of terms and discourses are both a reflection and a signal of their group membership/social position. For example, when reading the History section above you may have noticed that manufacturers of celluloid use the phrase 'motion picture film'. Whilst they need to use precise terms in order to differentiate between their different products and sectors (e.g. they also make film for still images), and in doing so stress an awareness of difference, others are less meticulous.

\section{Mainstream Press}

For this section I have looked at mainstream press and key sites in terms of usage of language such as Wikipedia, centering on central events/topics.

Although the Digital Cinema Society was set up in 2003, the mainstream press in the UK (such as The Times, Independent, Guardian, Daily Mail) and in the US (eg The Wall Street Journal and The New York Times) still uses 'film', as in 'the British film industry'. In the States 'movie' is also very much in evidence.

Using one of the most high-profile movie events as an indicator of current usage of terms, I looked at the 2014 Academy Awards or Oscars, which are overseen by the Academy of Motion Picture Arts and Sciences (AMPAS). As they state on their website http://www.oscars.org/, this is a prestigious event to which "hundreds of millions of movie lovers tune in to watch the glamorous ceremony and learn who will receive the highest honors in filmmaking."

The Oscars can be seen as an indicator of the industry, and it is clear that there has been a paradigm change in that although the most common term used in the categories is 'film', there is an increasing visibility of non-celluloid work and terms. For example there were shockwaves throughout the industry when the almost totally CGI/digital sci-fi drama Gravity won 7 Oscars ${ }^{1}$, including one for 'Best Film Editing'. Categorisation inconsistencies such as this (and the fact that they matter to many) make it clear that whilst there has been a move towards broader terms such as 'Best Picture' ${ }^{2}$ and 'Best Animated

\footnotetext{
${ }^{1}$ Oscars won by Gravity: visual effects, sound editing, sound mixing, cinematography, editing, original score, and Alfonso Cuarón won best director.

${ }^{2}$ won by Twelve Years a Slave, shot on $35 \mathrm{~mm}$ Kodak film with ARRI cameras
} 
Feature $^{1,}$, there is still a way to go towards both acceptance of the digital and clarity in the language, and not only within award ceremonies. For example, although Frozen won 'best Animated Feature' according to the Oscars website, the name of the award was translated into 'Best Animated Film' by The Hollywood Reporter (accessed 3/3/2014). There are other confusions:

For example, Wikipedia states that Gravity was 'filmed digitally on multiple Arri Alexa cameras'. 'Filmed digitally'? Surely there must be another way of saying that? Yes: a little later (and perhaps written by someone else) the entry says

'Most of the movie was shot digitally using Arri Alexa Classics cameras equipped with wide Arri Master Prime lenses. The final scene, which takes place on Earth, was shot on an Arri 765 camera using $65 \mathrm{~mm}$ film to provide the sequence with a visual contrast to the rest of the film.'

So again we have 'movie' and 'film' used interchangeably (at the beginning and end of that quote), but at least it was 'shot' on a digital camera, rather than filmed on one!

One of the biggest online film-review forums Rotten Tomatoes avoids using 'film' by choosing the categories 'Movies', 'TV', 'DVDs' to divide content. $\mathrm{IMDb}^{2}$ (Internet Movie Database) - "the world's most popular and authoritative source for movie, TV and celebrity content" - uses the topline categories 'Movies, TV and Showtimes, but within each article, for example those connected with Gravity (which, due to the mass media coverage of the awards, is widely known to be digital), they say 'the film'.

\section{Academia}

In UK universities there appears to be an increase in the use of terms such as 'digital culture', and 'moving image', but the majority of courses are still called something like 'Film Studies', or even 'Digital Film Production' (as at the University of Worcester). The choice of name matters, as it signals course content as well as whether making (or not making) the distinction between digital and film is deemed important. It may be that making the distinction signals 'interest in practice', whereas not making the distinction signals 'focus on theory'. As yet it is too early to say what the dominant interpretation/use

\footnotetext{
${ }^{1}$ won by Frozen, 'a 2013 American 3D computer-animated musical fantasy-comedy film produced by Walt Disney Animation Studios and released by Walt Disney Pictures' according to Wikipedia.

${ }^{2}$ As well as a wide lay-man readership, IMDb allows industry professionals such as actors and crew to post their cvs for an annual fee.
} 
will be. I suspect that Sean Cubitt's forthcoming book (due Autumn 2014) will be an interesting continuation of the debate ${ }^{1}$ of the meaning of the change.

If there appears to be a reluctance to differentiate between celluloid and digital production in general conversation, media reports, and university usage, what about in the trade press? Because expertise in celluloid is different from expertise in digital, and there has been much debate about the two forms, one might expect choice of terms to be very precise.

\section{Trade and Trade Press}

'Both [film and digital] are 'just a tool'. 'Horses for courses.' You need to choose your tool depending on your script/story, project and budget. In my opinion, the story is the most important thing in cinema/TV, and the pictures should complement the story and shouldn't get in the way of storytelling."

(Professional focus-puller/DoP)

Trade press is written by and for experts, and as such can be understood as a display of expertise. Within the trade press much has been made of the difference in the aesthetics and workflow of the two media. As more professionals become proficient with digital cameras there has been an increase in statements such as "No camera/format is best for everything", although there are still those championing film for its aesthetics and for "capturing the moment'. In my interviews with practitioners (especially younger ones) I've noticed that they often nod to that discourse, but always highlight the accessibility \& potential of digital imaging technology:

"I see digital as heightened quality, providing a lot more manipulation, and its inexpensive nature gives options for experimentation more. Film has a classic and nostalgic feel that can't be replicated, I see it as a representation of Hollywood and something becoming extinct."

(Final year undergraduate)

Note how film has become associated with nostalgia. In the 1970's within the UK television industry the 'film' professionals - ie those working with celluloid - protected their industry status by positioning themselves and their work as better than those 'Johnny-come-lately's using the upstart digital media. As Cubitt pointed out, 'The ideology of professionalism is deeply entrenched in British moving-image media: the idea of letting a user group free with recording equipment almost unthinkable' (1991, p149). As a participant told me, "Over here [the UK] they wouldn't touch video with a

\footnotetext{
${ }^{1}$ See work from the mid 2000's by for example Mary-Anne Doane, Janet Harbord, Laura Mulvey, DN Rodowick. However, their focus is primarily content and viewing, rather than on production-related hierarchies..
} 
barge pole" (cinematographer, conversation Feb 2014). Yet from this position of dominance in television and cinema, film has rapidly become a nostalgic minority technology.

As old habits and expectations die hard, it is perhaps not surprising that film is still spoken of within the industry as the benchmark to which digital should aspire. From this point of view, the use of 'film' to describe a digital piece could be understood as a compliment, a gesture towards inclusion in the higher-status category, but conversation with early video practitioners suggest that they see it as a gesture which suggests and maintains film (and film practitioners) as the higher-status category.

It is perhaps useful to consider the discourses of two influential trade 'voices': The Digital Cinema Society and the American Society of Cinematographers.

The 'old boys' American Society of Cinematographers (created in 1911) and 'newcomers' Digital Cinema Society (created 2003) are high-status influential sources of information and knowledge. ASC membership is small and elite - an invitation is considered a high honour, and is extended only to directors of photography and special effects experts with distinguished credits in the film industry. Its monthly magazine American Cinematographer International Journal of Motion Imaging (first published in 1920) concentrates on technical coverage of recent releases, and has a wide readership. These publications function as demonstrations of the current desirable discourse.

The Digital Cinema Society (international membership nearing 6,000) was founded in 2003 as 'a nonprofit educational cooperative dedicated to the industry's informed integration of new technology', and positions itself as technologically neutral: 'The Society's purpose is not to advocate for digital technology, but to objectively examine all media, solutions, services, and technologies without favoring any one brand, service, or format over another.' (http://www.digitalcinemasociety.org/digital-cinema-society, accessed 29th June 2014).

The president of each of these two societies has recently made statements about digital and film:

'Despite the endless arguments about the switchover from film to digital acquisition - many of which continue, ridiculously, to this day - ...' (Richard Crudo, ASC, Feb 2014),

and

'We especially don't need to differentiate between movies shot on film or acquired digitally...' (James Mathers, DCS, Jan $31^{\text {st }} 2014$ )

There are a number of things to note here. Firstly, the change to digital acquisition is an important one for the ACS readership, otherwise there wouldn't be 'endless arguments'. The word 'ridiculously' is an important choice, especially when made by the president of the association. 
The DCS president emphasises the parity of film and video (ie video is no longer the underdog), but despite saying that they don't have to differentiate, they still produce 'an annual list of all major motion pictures and TV Dramas that were acquired digitally'. This is presumably done because their readership still wants to know these stats, and the stats definitely make the point. As the DCS president states:

'with the subsequent growing acceptance of digital, and the vast number of major productions using it, the task became overwhelming and we had to give it up. However, we were still interested in seeing a current ratio of digital compared to film production, and undertook an informal survey using IMDBpro (Internet Movie Database, an Amazon company) as the source.'

(Mathers, DCS Dec 31st 2013).

It is clear that this is a period of transition in hierarchies and in usage and acceptance of terms and practices.

James Mathers describes himself as a cinematographer rather than as 'digital cinematographer' or 'film cinematographer' ( cf his Jan 31st 2014 post, quoted below), but intriguingly he describes his posts' readership as 'Filmmakers' (Feb 27th, 2014 post).

\section{Motionographer, Virtual Cinematographer, Director of Imaging? Role Evolves, Title Remains: Cinematographer}

As a Cinematographer, I've had to get used to the fact that my role is constantly changing, and while I don't think it is necessary, some have even suggested a new name for what we do. Whatever the specific skill-sets employed, we are still charged with guiding the cinematic motion image to the screen. That screen might be theatrical, TV, or mobile device. It does not matter the display medium or the capture format. I'm not now a "Digital Cinematographer" any more than I was a "Film Cinematographer" over the many years I acquired images on celluloid. The technology doesn't define us; it is rather just a tool to help us achieve our creative intent. It is a means to an end, not the end itself. -

(Mathers, DCS Jan 31st 2014)

James Mathers makes a clear case for the incorporation of digital technology and know-how in the industry, which might be interpreted as an olive branch from the new victor, a mollifying attempt made by someone from the 'outsider' camp who has suddenly found themselves in a position of authority and high status. However, others fight for distinction between the two media. 


\section{Costs, Workflow, and 'Fix it in Post'}

One of the biggest differences between shooting in film and shooting digitally is that with film the costs (of the camera, of the film, of developing, of the projection) are high, restricting practice and knowledge to the professionals (although of course there have been and still are keen amateurs), whereas digital equipment and software for capture, processing/editing and display is far more accessible.

The other big difference is that with film you don't know what you've got until it is processed, which means that there is a high risk of making expensive mistakes, which increased the demand for highly skilled operatives. In contrast, shooting with a digital camera means that you can see what you've got straight away. Perhaps because of this, digital, especially with the explosion of cameras for the domestic market, became seen as amateur.

Digital moving-image cameras are now available to the amateur in a way that film cameras have never been (now even children expect their phones to capture moving images). However, the top-end digital cameras (Twelve Years a Slave and Blue Jasmine used ARRI CAM; Gravity and Dallas Buyers Club used ARRI Alexa, and RED Epic kit was used to shoot The Hobbit) are definitely beyond the budget of most of us, never mind the enormous computer power required to edit that volume of data. But the prices are tumbling, as is the price of high-quality scanning equipment (ie equipment which converts film to digital) - cf Blackmagic's 2012 launch of the \$3k “3K”, and the 2014 Kickstarter-funded \$3k 'Digital Bolex D16'.

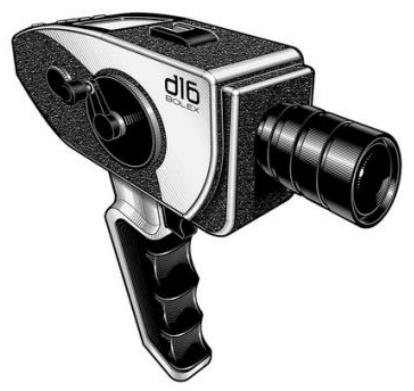

Bolex D16

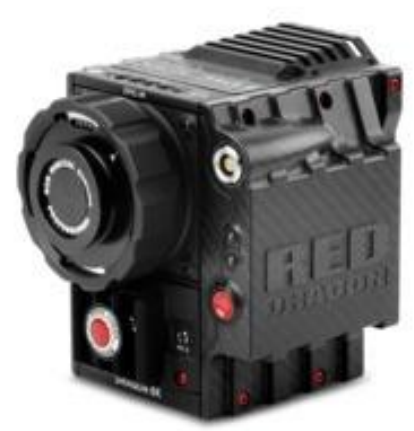

EPIC-M RED Dragon (carbon fiber) w/side SSD module (Carbon fiber) and magnesium lens mount.

Price $\$ 50,000.00$

(Source: https://www.kickstarter.com/projects/joedp/the-digital-bolex-the-1staffordable-digital-cinem Accessed 29 June 2014)

(Source: http://www.red.com/store/cameras Accessed 31st March 2014)

Because during image capture digital storage is cheaper than film and the speed of storage and retrieval has increased hugely, the people working on 
digital shoots tend to generate many more recorded minutes. That means that although both film and digital post-production involves similar tasks - grading, colour-correction, sound editing, editing, addition of special effects etc. - there may be more post-production decisions for digital acquisition than with film.

As a direct consequence of digitisation and software developments, the importance of various roles in the workflow is changing. To film-based cinematographers the phrase 'fix it in post' has come to sum up all that is bad about digital. To paraphrase from many conversations, this is because whereas historically 'the look of the thing' was decided by the cinematographer, now everything that is done in front of the lens can be changed post-production by 'a spotty teenager' with tech know-how but without the training, skill, and over-arching view and remit of the traditional cinematographer - something which traditional cinematographers feel is forgotten.

A recent example of this is Christopher Doyle's tirade against Life Of Pi's cinematography Oscar award: "since 97 per cent of the film is not under [the cinematographer's] control, what the fuck are you talking about cinematography, sorry. I'm sorry. I have to be blunt and I don't care, you can write it. I think it's a fucking insult to cinematography" (K Jagernauth, 2013). When meanings of words change (especially when they do so so publicly), hierarchical positions and 'the way it is done' are challenged, and feelings clearly run high. Whilst film is associated with the rather romantic idea of 'capturing the moment' and the haptic experience of working with the material, digital is associated with multiple recordings and post-production by technogeeks rather than artists. The ASC draws on example of an artist to remind the profession what they're losing:

'[Tacita Dean's] film presents a compelling but gentle argument for the human qualities that seem inherent in working with film, not the abstraction via electronics of zeroes and ones. The physicality, tactility, even olfactory qualities of film support an experience that is for her deeply visceral, sentient. This is not about technique, but about the experience of the human body engaged in intimate, direct contact with the medium itself.'

(Source: John Bailey's blog, July 2012)

\section{Summary}

The path of digital motion capture and display from rank outsider to serious contender and now equal presence - perhaps even victor - within the moving-image industry has not been welcomed by all. Lines have been drawn in the sand and choice, use and interpretation of term have been a central element in defining the warring discourses. Some (notably those in the video camp) have sometimes reacted fiercely to the lack of distinction made by key players. Others have tried to smooth away distinctions, seeking to end the 
'ridiculous' antagonistic discussion re difference. As one very influential industry player put it:

"Distribution on film is totally dead now but [the Blackmagic scanner] actually gives origination on film a boost!

$16 \mathrm{~mm}$ [film] scanned [ie converted to digital format] at either 3 or $4 k$ looks amazing."

(Source: senior cinematographer, personal email)

And as another said:

"The real problem of film is not the medium itself - it's the large corporations that dominated its handling. If smaller companies get involved then everything's possible. But neither film nor digital is magic - they're simply media of acquisition - Cinematographers are sometimes the main obstruction by being too nostalgic and sentimental!"

(Source: personal email)

In the 1970s digital was new and largely restricted to television work and experimental artists, and was fiercely resisted by many of the 'old guard'. Over the last 10 years there has been a surge in interest and acceptance of digital by the motion picture industry, in large part due to economic pressure from distributors, vast improvements in digital AV technologies (software and hardware), and the push from young practitioners who've grown up with digital. As is likely to be the case with any changes in dominance, voices of authority have taken up positions of defence, attack, and amelioration, and over time many of those discourses may change. Whilst film is not yet dead, the rapid loss of film-camera equipment, celluloid manufacture/processing facilities, and of cinemas with film-projection equipment in the last 3 years suggests that in practical terms it is already a marginal format. In this context the BFI's refusal to update its 'Film Forever' slogan seems rather ironic:

\section{B. Film}

So, who decides if it is a 'film', or a 'movie'? What would you prefer to call it? And what would that say about you? 


\section{References}

Bailey, J., July 2012 blog for The American Society of Cinematographers http://www. theasc.com/blog/2012/07/02/tacita-dean-at-the-tate-turbine-hall-a-farewell-tofilm/. Accessed 31st March 2014

Barthes, R., 1972, Mythologies, trans A. Lavers, Paladin, London.

Bourdieu, P., 1984, Distinction, trans R. Nice, Harvard University Press, Cambridge Massachusetts.

Burkhart, J., 3 June 2013. Source: http://www.redsharknews.com/business/item/773can-blackmagic-resurrect-film. Accessed 31st March 2014

Crudo, R., Feb. 2014, President's Desk, ASC, Source: http://www.theasc.com/ac_ maga zine/February2014/PresidentsDesk/page1.php. Accessed 31 ${ }^{\text {st }}$ March 2014

Cubitt, S., 1991, Timeshift: On Video Culture, Routledge,

1998, Digital Aesthetics, Sage Publications, London,

2013, 'Angelic Ecologies', Millennium Film Journal, 10/2013, Issue 58,

2014 'Ecomedia Futures', International Journal of Media and Cultural Politics, Volume 10, Issue 2 (June)

Enticknap, L., 2005, Moving Image Technology- From Zoetrope to Digital, Wallflower Press, London.

Fuji, 2012, ‘Announcement on Motion Picture Film Business of Fujifilm' http://www. fujifilm.com/news/n120913.html. Accessed 3/3/2014. 2013, 'Discontinuation of Motion Picture Film production' http://www.fujifilm.com/news/n130402.html. Accessed 3/3/2014.

Harbord, J., 2002, Film Cultures, Sage Publications, London.

2006, 'Digital Film and 'Late'Capitalism: A Cinema of Heroes?' in J. Curran and D. Morley (eds) Media and Cultural Theory, Routledge, Abingdon.

2007, The evolution of film: rethinking film studies, Polity Press, London.

Jagernauth, K., March 14, 2013 10:21am Source: http://blogs.indiewire.com/theplay list/christopher-doyle-calls-life-of-pi-a-fucking-insult-to-cinematography-hateson-lincoln-more-20130314. Accessed 3/3/2014.

Kodak, 2013, 'Kodak Reaches Motion Picture Film Deal with 20th Century Fox Six Hollywood Studios Now Have Agreements with Kodak' http://motion.kodak. com/motion/About/News/2013/Jun03_1.htm. Accessed 3/3/2014.

Mathers, J., $31^{\text {st }}$ Jan 2014, DCS http://www.digitalcinemasociety.org/ essay/motion ographer-virtual-cinematographer-director-of-imaging-role-evolves-title-remainscinematographer. Accessed 3 March 2014.

Manovich, L., 2013, 'Media After Software', Journal of Visual Culture 12 (1).

McLuhan, M., 1994 (1964), Understanding Media: The Extensions of Man, MIT Press, Cambridge, Massachusetts.

Rodowick, 2007, The Virtual Life of Film, Harvard University Press, London.

Waugh, R., 2011, Updated: 18:00, 16 November 2011, Source: http://www.dailymail. co.uk/sciencetech/article-2062289/Digital-cinema-eclipse-35mm-film-early-20 12--celluloid-disappear-2015.html. Accessed 3/3/2014. 
